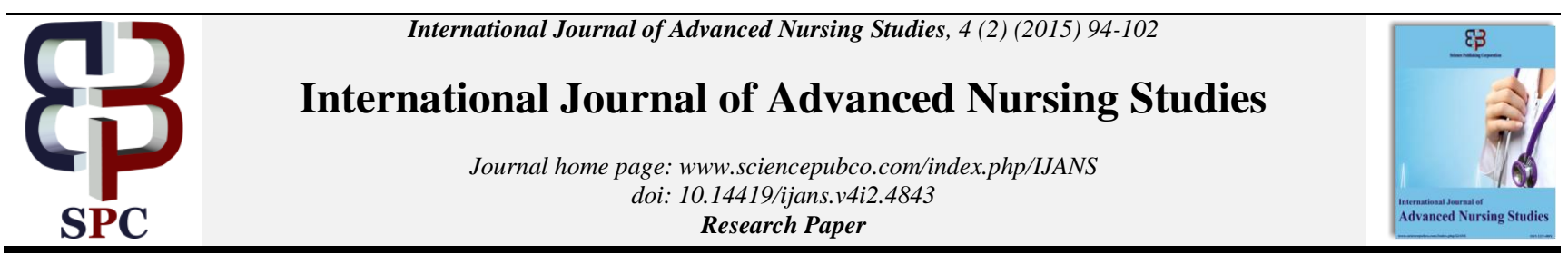

\title{
Reflective practice programme for registered nurses in training hospitals in Windhoek
}

\author{
Lucia N. Nelumbu \\ University of Namibia, Private Bag 13301; Windhoek; Namibia \\ E-mail: Inelumbu@unam.na
}

\begin{abstract}
Problems or incidents occurring in clinical settings are often seen as indicators of poor nursing care and even indicators of a lack of reflective practice skills. A qualitative, explorative, phenomenological, descriptive and contextual approach was conducted to explore and describe how reflective practice is practised by registered nurses in training hospitals in Windhoek. The findings revealed inadequate knowledge of reflective practice among registered nurses. Based on these findings the educational programme was developed to facilitate learning and application of reflective practice in clinical practice. This paper presents the description of an educational programme that was developed to facilitate learning and practice of reflective practice by registered nurses to make a difference to their patients' care.
\end{abstract}

Keywords: Nursing Process; Kolb's Experiential Learning Cycle and Rolfe's Framework.

\section{Introduction}

This article is extracted from the author's study, "An Educational programme to facilitate reflective practice as registered nurses in training hospitals in Windhoek. The author was convinced that the development of a reflective practice programme would enhance the proper application of reflective practice in clinical settings by the registered nurses and prevent them from performing daily activities simply as a routine without engaging into reflection. This was also justified by the responses gained from the participants, who showed little insight into the concept of reflective practice, as they only expressed the execution of their daily activities without paying attention to how they reflect in daily practice.

\section{Purpose}

The purpose of the educational programme was to:

- enhance knowledge and skills to effectively address the clinical challenges which the registered nurses may encounter in terms of reflection;

- encourage them to develop reflection in order to deliver quality nursing care to patients;

- facilitate the nurses' abilities to be critical in order to facilitate useful change towards better patient care;

- consolidate existing knowledge and skills from the learned theory and practice and to grant the registered nurses an opportunity to gain wider and more varied knowledge and skills on the concept of reflective practice;

- Provide nurses with necessary information on the aspects entailed in the programme and how this programme would guide them throughout their daily practice, by paying attention to reflection.

The rationale behind the development of an educational programme of reflective practice is presented with a diagrammatic representation and discussion of each of the five steps of the nurs- ing process which underscore the integration of reflective practice in the nursing process.

The framework in the development of the educational programme to facilitate reflective practice is displayed in Figure 1 below.

\section{Philosophical approach of the programme}

In the developmental phase of the programme the author employed humanistic philosophy. 'Humanism' as a term is defined by Traynor (2009) as a concept which includes the ideas of groups whose beliefs appear to be indirect contradiction to each other with its focus on the dignity, rational abilities and value of all people. The humanistic approach reflects an attitude of caring and respect for others, an attitude which finds value in all people. The central assumption of humanism is that people act with intentionality and values (Glassman \& Hadad, n.d.).

In order for the implementation of the developed programme to be effective, the facilitator was expected to conduct the workshop in a very humane way. The facilitator applied humanistic characteristics such as showing respect to the participants. On the other hand, the facilitator has also ensured the conducive environment for the participants where they could be involved and share their knowledge. 


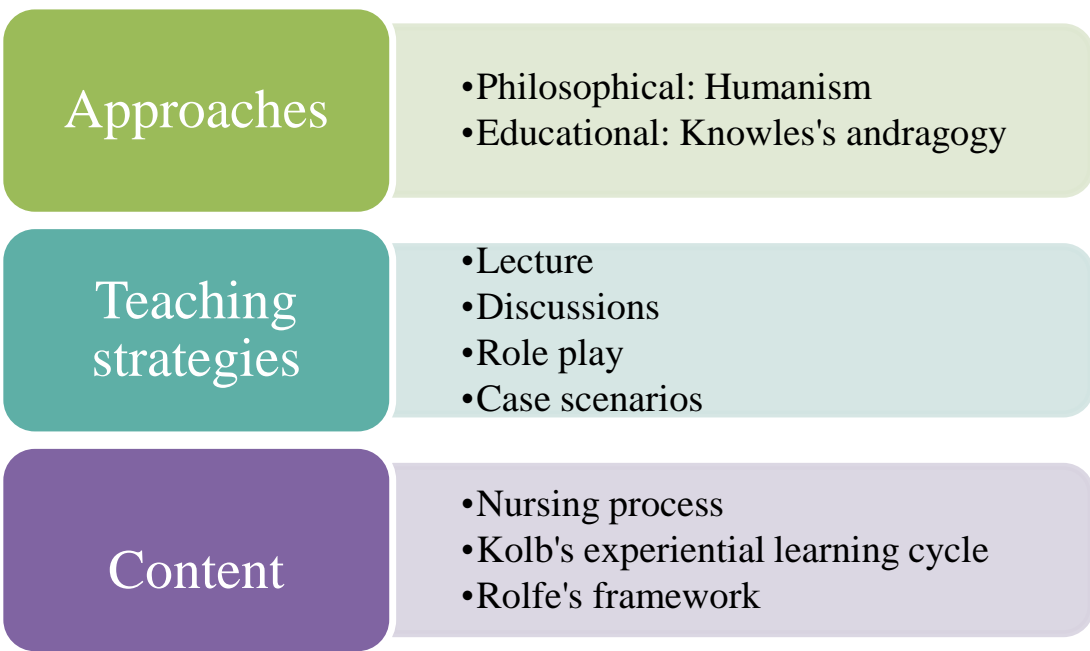

Fig. 1: Framework for the Development of the Educational Programme to Facilitate Reflective Practice.

\section{Educational approach of the programme}

The educational approach of the programme is guided by andragogy as an approach of education. Andragogy is a set of assumptions about how adults learn (Fidishun, n.d.). As such it maintains that people become adults psychologically when they arrive at a self-concept of being responsible for their own lives, of being selfdirecting (Caruso, 2010).

How educators approach the subject matter, and the students' motivation is determined by the andragogical philosophical underpinnings of educators' teaching practices. Nursing education as a component of tertiary education is a situation that requires andragogical dynamics. The concept of andragogy was popularised by Malcolm Knowles. This theory was an attempt to differentiate learning in childhood from learning in adulthood (Keese, n.d.). His ideas still provide a practical instructional guide for all ages, especially adults. This adult learning theory (andragogy) is also of relevance to the registered nurses who participated in this study, for they too were considered as adult learners.

The following six assumptions under Knowles's andragogy namely, self-concept, experience, and readiness to learn depend on need, a problem-centred focus and internal motivation, and adults need to know why they need to know something (Caruso, 2010; Atherton, 2011; Smith, 2002). These assumptions, with their relevance to this programme, can be described as follows:

- Self-concept. The idearefers to an adult becoming more selfdirected and independent as he/she matures. Adults may choose what they want to learn, why they want to learn it and how they want to learn it. This concept applies to this programme because registered nurses need to be actively involved in the learning of new concepts and to understand the benefit of them.

- Experience. Thisrefers to the situation where adult learners have a wealth of life experiences that they bring with them into new learning experiences. For this programme it refers to registered nurses with vast nursing experience, who are expected to contribute to group activities and are seen as valuable resources for learning from and with each other.

- Readiness to learn depends on need. Whether or not an adult is ready to learn depends on what they need to know in order to deal with life situations. For this programme registered nurses are expected to learn new concepts like reflective practice in order for them to be able to apply it in their daily practice.

- Problem-centred focus. This concept refers to the fact that adults need to see the immediate application of learning. Therefore for this programme it implies that registered nurses need to learn the application of reflective practice during their daily practice in order to provide quality patient care.
- Internal motivation. This means that adults would seek learning opportunities due to some external motivators, and the most potent motivators (self-esteem, better quality of life, and self-actualization) are internal. For this programme active participation by the registered nurses should be driven by their intrinsic motivation to learn all about reflective practice and the rationale behind it in nursing practice.

- Adults need to know why they need to learn something. Adults need to know what's in it for them-how this new knowledge would solve a problem or be immediately applied. In this programme it is important for registered nurses to know and understand the better results that emanate from the knowledge of reflective practice, the improvement of traditional provision of patient care.

\section{Teaching strategies}

Different teaching strategies, such as a lecture with discussion method; group discussion; the guided discussion method, role play and case scenario were employed, as the best ways to convey the necessary information.

A lecture method is the most common used form of presentation and is used for the introduction of new subjects, summarising ideas, showing relationships between theory and practice, and reemphasising main points. This was ideal to use during the introduction of the new concepts such as reflection, Kolb's experiential learning cycle and Rolfe's model of reflective practice.

\section{Outline of the content of the educational programme}

The content of the educational programme focuses on the concepts of reflective practice and its relationship to the nursing process. The educational programme demonstrates the process of reflective practice based on Kolb's experiential learning cycle and the framework of Rolfe. It addresses aspects pertaining to nursing education in order to provide quality patient care. The main focus of the programme remains reflective practice within the nursing process, with the aim of teaching registered nurses how to reflect during their daily practice.

The following will form the basis of the content of the programme:

\subsection{The nursing process}

In order for the registered nurses to understand their roles and functions in caring for patients, they need to strengthen the nurs- 
ing process and understand it so that they would be able to apply the knowledge of reflective practice in their daily practice.

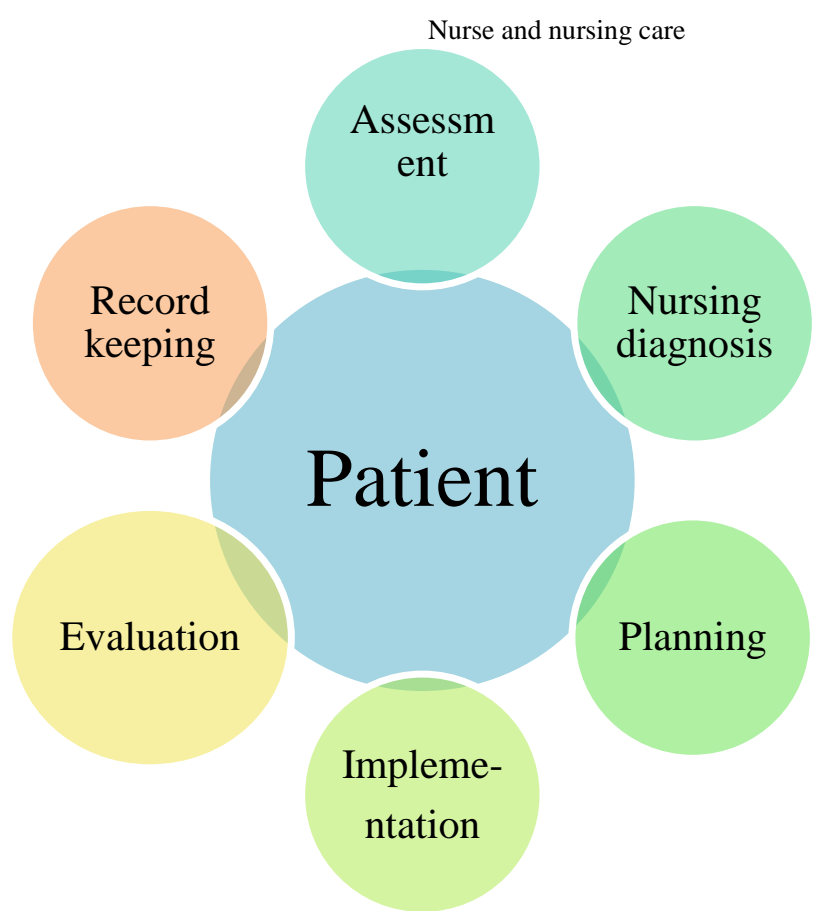

Fig. 2: The Nursing Process Diagram.

The nursing process refers to the relationship or interaction between a patient and a nurse as shown in figure 2 above. As stipulated in the literature, this dynamic and efficient problem- solving technique need not be reserved only for patients but also for nurses to approach the problems in their lives (Bloniasz, 2011). The nursing process focuses on the domains of patient assessment, nursing diagnosis, planning care, implementing care, evaluating care, and record keeping.

This phenomenon is also described by Bulson and Bulson (2011) as a deliberate, problem-solving approach to meeting the health care and nursing needs of patients.

Thomas, Bertram and Allen (2012) emphasized that competent critical reasoning, problem solving, decision making and professional communication are essential skills required for safe patient care.

Within the nursing process framework we can find the Structured Observation and Assessment of Practice (SOAP) described as a full-day holistic practice-driven clinical competence assessment approach that motivates nursing students' learning, promotes critical reflection and confirms graduates' readiness for professional practice (Levett-Jones, Gersbach, Arthur and Roche, 2011). In order to successfully use this nursing process, reflection is an important element thereof. To enhance the concept of reflection within the nursing process participants of the programme should first understand the concept of reflection which would be taught through Kolb's experiential learning cycle. The relationship between nursing process, Kolb's experiential learning cycle and Rolfe's framework is illustrated in Table 2.

The content of the nursing process would be described as following:

Assessment

It is important for registered nurses to have knowledge and skills on how to perform needs assessment as part of their roles and responsibilities. They also need to develop health indicators and methods to measure patients' outcomes. During this stage all the available information about the patient's problems or needs should be determined accurately and factually. This also allows registered nurses a good chance to assess the likely impact of care on patients.

According to Karimi (2011), assessment is described as the collection and interpretation of information and this information is used in the three types of professional judgment within the nursing process, which are: diagnostic judgment-the identification of potential health problems; therapeutic judgment-decisions about intervention, outcome and evaluation; and ethical judgment identification of an actual or moral problem. As such, assessment is important for establishing the severity of threat to life and hence the need for medical intervention. During the assessment stage the patient's needs become obvious and the registered nurses may identify opportunities for initiating simple and effective interventions. The reassessment of patients in response to nursing interventions as well as to potential deterioration is important.

Nursing diagnoses

The facts about the patient's problems can be used to help predict an expected response. This diagnosis allows registered nurses' sense to determine how the response will affect patient care. Here the nurses use critical-thinking skills to interpret assessment information and identify client strengths and problems.

Nurses use nursing diagnoses as the basis for providing adequate nursing care. It was further pointed out that an accurate nursing diagnosis is essential for providing high quality nursing care. Nursing diagnoses are described as clinical judgments about individual, family or community responses to actual or potential health problems/life processes (Paans, Sermeus, Nieweg,\& Van Der Schans, 2010).

The literature also indicated that reasoning skills include both inductive and deductive skills, such as skills in the analytical, inference and evaluation fields that are essential for the diagnostic process. However, it was indicated that little information is available on how specific reasoning skills affect the formulation of accurate nursing diagnoses (Paans et al., 2010).

Planning

For planning, registered nurses need to have knowledge of how to define their objectives, use their critical-thinking skills, set priorities and come at the conclusion on what should be changed. The patient is the one who benefits from the knowledge and competence of the nursing staff in this regard. This involves the notion of accurate diagnosis that will allow registered nurses to begin to prepare for the plan of action.

According to the literature, the nurse refers to the client's assessment information and diagnostic statements for direction in formu- 
lating client goals and designing the nursing interventions (Karimi, 2011).

Some authors, among others Dennill, King and Swanepoel (2007), suggested that adequate planning should assure people that they will have input into organized health education efforts. They further pointed out that the planning process, ending with a plan, should give answer to the following three questions:

- What are we trying to achieve?

- What are we going to do?

- How would we know whether we have been successful?

- Based on the abovementioned suggestions, planning should focus on the following:

- Prioritising of the patient needs and deciding which needs urgent attention;

- assessing the presence of a need and its effects on the patient; and

- Planning to meet the need which is the highest on the priority list.

The above ideas should be employed for the enhancement of the development of a reflective practice programme.

Implementation

The plan should be put into action once it is developed. Implementation should indicate how the knowledge and skills are to be applied to solve the problems. This is the implementation of the plan, the time for action. This is in line with Karimi (2011), who holds that in the nursing process implementation is the action phase through which the nurses need cognitive, interpersonal and technical skills. She further explained that while implementing nursing care, the nurse continually assesses the patient and his or her response to the nursing care.

At this stage, registered nurses are expected to put the programme into practice and at the same time they should evaluate the process through reflection-in-action.

Evaluation

The portfolio is very important. Each registered nurse must complete and keep the portfolio. The purpose of the portfolio is that of an evaluative tool which includes outcomes achieved in clinical practice. This also includes the registered nurses' reflections upon performed activities during clinical practice. This reflective practice happens over time as the registered nurses practice.

Evaluation involves an in-depth analysis of the plan, concentrating on the following:

- Evaluation of the success or failure of the plan and

- Strategies of re-planning in case of the failure of the original planning.

The question should be asked whether the actions are meeting the need of solving the problem of the patient.

It has been stipulated that the judgement of the value of the programme can be about the outcome-what was achieved and about the process-indicating how it was achieved. The literature further clarified the components of evaluation as outcome evaluation focusing on the extent to which the goals and objectives of the health education programme have been met, irrespective of how well organized or how efficient the programme was (Dennill et al., 2007).This is in accordance with Bloniasz (2011), who maintains that this is a dynamic process with no mistakes, just learning opportunities. Furthermore it was pointed out that during evaluation, the nurse and client together measure how well the client has achieved the goals specified in the plan of care (Karimi, 2011). In this context the nurse can answer the following questions:

- Were the nursing diagnoses accurate?

- Did the patient achieve the expected outcomes within the critical time periods?

- Have the patient's nursing diagnoses been resolved?

- Have the collaborative problems been resolved?
- Do priorities need to be reordered?

- Have the patient's nursing needs been met?

- Should the nursing interventions be continued, reserved or discontinued?

- Have new problems evolved for which nursing interventions have not been planned or implemented?

- What factors influenced the achievement or lack of achievement of the objectives?

- Should changes be made in the expected outcomes and outcome criteria?

Record keeping

Records and recording are essential elements of reflective practice. Registered nurses should decide what details to keep. These records should reflect the quality of their clinical role. Although recording is one of the essential aspects of nursing, this seems not to have been consistently maintained throughout the history of this profession. Earlier literature indicated that nursing documentation confirmed the nursing process, while later studies reported a deficiency in nursing documentation (Hayrinen, Lammintakanen, \& Saranto, 2010). However, registered nurses and all healthcare professionals, as well as student nurses should record all phases of the nursing process in the nursing care plan.

Each phase of nursing process affects and depends on the other phases; they are closely interrelated interdependent and recurrent. It was further argued that the use of the nursing process provides a means of assessing nursing's economic contribution to client care (Karimi, 2011).

\subsection{Kolb's experiential learning cycle}

Kolb's (1984) definition of learning describes knowledge as being generated through experience (Adamson, 2011). Hence Fowler (2008) pointed out that both Dewey and Kolb appeared to agree that experiential learning is the product of reflection upon experience with the nature of the reflection and the quality of experience being significant to the overall learning.

Experiential learning is also defined by Johnson, Sonson and Golden (2010) as the process whereby knowledge is created through the transformation of experience. Knowledge results from the combination of grasping and transforming experience. The concept is further described by Ayob, Hussain, Mustafa and Shaarani (2011) as the process whereby knowledge is created through the transformation of experience.

One of the recognised methods of learning, the standard of which would also help is Kolb's experiential learning cycle. Kolb, being the pioneer of the theory of experiential learning, developed a four-stage cycle underlying learning. One of its elements is reflection upon which many authors based their theories of reflective practice. James and Clarke (1994) pointed out that many of the attractions of reflective practice are the reflection which is grounded in a growing understanding of forms of practical knowledge and of experiential learning. Again, these authors argued that in the status currently being given to reflective practice in nursing, it is an accepted view that reflection will lead to better practice and to greater competence.

The educational reflective practice programme is to be facilitated through an experiential learning approach. According to Wessels (2005), experiential learning is an extension to the formal education component normally provided by the educational institution; it may assume various forms. Experiential learning is furthermore defined by Quinn and Hughes (2007) as learning by doing, rather than by listening to other people or reading about it.

The experiential learning cycle as described above is illustrated in Figure 3. 


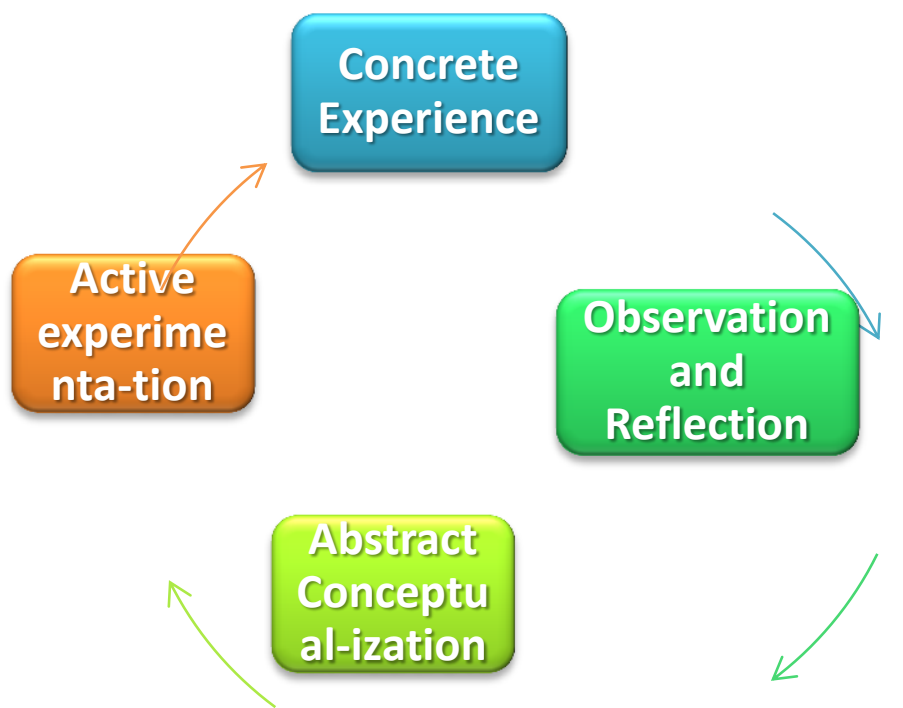

Fig. 3: Kolb’s Experiential Learning Cycle.

Keene (2009) also sees experiential learning as enhancing the movement of new theory and the conversion of theory from shortterm to long-term memory.

On the other hand, the idea of the taxonomy of experiential learning in which the learning experience moves from exposure through participation, identification, internalisation and finally dissemination was developed (Fowler, 2008). Thus learning results from the coming together of experience of a certain quality, with meaningful reflection (Fowler, 2008). The representation of this is shown in Figure 4 below:

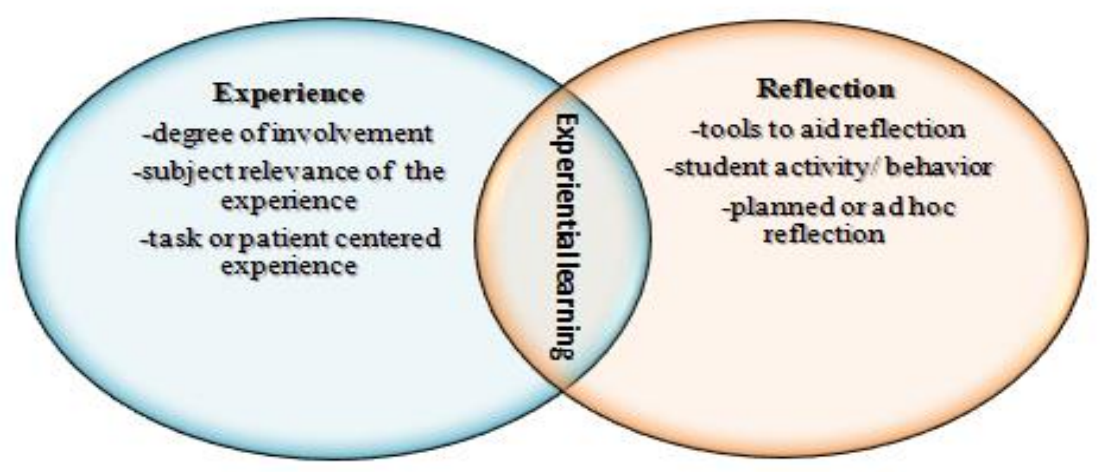

Fig. 4: Experiential Learning (Fowler 2008).

The content of Kolb's experiential learning is discussed in detail below:

\section{Concrete Experience}

This first level as illustrated in Figure 3 is based on an inquiry concerning something which happened. It focuses on the identification of the problems of practice. Since the purpose of reflective practice is to improve the professional's performance and because problematic experience plays an important role in learning, inquiry is needed (Kolb, 1984).

It is argued that the use of concrete experience refers to the testing of ideas and the use of feedback to change practice and theories To support this it was also explained that experience gives food for reflective thinking, which in turn leads to abstract conceptualizations and hypotheses to be tried out through active experimentation (Smith, 2001; Kohonen, n.d.).

\section{Observation and reflection}

This level as illustrated in Fig.3 refers to learning by perception and emphasises the understanding of ideas and situations by careful observation. Registered nurses should describe their experiences, then reflect on them and consolidate them. Reflection exists to provide guidance and help registered nurses to look back over challenges or events which happened, to review them and change them into learning experiences. Reflection is described as a conscious, dynamic process of thinking about, analysing and learning from a clinical experience, enabling the nurse to gain insight into, itself and into practice. It is further viewed in the literature as a central level of professional practice and a mechanism for continued professional development (Gustafsson \& Fagerberg, 2004; Jarvis, 1992; Jasper, 2003; Asselin, 2011,).

Reflection has also been described as the process of critically assessing the content, process or premises of efforts in order to interpret and give meaning to an experience, as well as a critique of our assumptions in problem solving (Binding, Morck, \& Moules, 2010; Schön, 1987).

Reflection is described in the way that it includes thinking about what you are doing while you are doing it, trying to discover why things went wrong, considering what helped to make something go really well. Similarly it is a way for nurses to explore the depth and complexity of their practice, to make sense of why they do what they do, to capture the art and creativity of practice, to explore the emotional aspects of a situation, and to attain a rich understanding of nurse-patient interactions (Asselin, 2011; James \&Clarke, 1994; Jones, 2004; Levett-Jones, 2007; Thompson \& Burns, 2008). 
The concept of reflection entails the aspects of recollection and the rehearsal of the content of what is recollected; experiential reflection involves remembering the event as it occurred and the associated feelings and thoughts-a revisiting of the experience. Reflection relates to the cognitive interest as moral and ethical reflection (Stein, 2000-2001; James \& Clarke, 1994).

It was stated that registered nurses, for example, needed to reflect on experiences and be asked to observe the experiences, thinking of many perspectives. Thus registered nurses should reflect on aspects like the environment where they find themselves, who they are and what they are capable of through engagement with others. This is based on the notion that the ability to reflect and respond to our own and others' reflections is a skill that needs to be adopted by every registered nurse (Kolb, 1984).

\section{Abstract conceptualisation}

During the third stage of Kolb's experiential learning cycle as indicated in Figure 3 the focus is placed on the definition or description and classification of abstract ideas and concepts in order to have precise conceptual categories. This level encourages registered nurses to make an appropriate decision by using the concepts formed so that they can make a conclusion from past and present experience. This involves the ability to construct a plan of action to address the problems. According to Kolb (1984) learners (here, registered nurses) should be able to develop concepts that enable them to integrate their observations into useful theories.

\section{Active implementation}

In the fourth and last stage of the experiential learning cycle registered nurses are now at the stage where they can plan, and apply the new learning from their previous experiences. During this stage, they might also try and record an event where they are aware of reflecting-in-action, and then also apply retrospective reflection to the same events. According to Kolb's experiential learning cycle, at this stage the registered nurses should be able to transform the developed concepts into decisions and to solve problems (Kolb, 1984).

Experimentation is well understood because it is based on application through action in a new circumstance within a range of generalisation. This means that action is taking place in a different set of circumstances and the learner is now able to anticipate the possible effects of the action. It is emphasised that caring is central to the philosophy of nursing and has offered theoretical frameworks for nursing care (Smith, 2001; Ranheim Kärner, Arman, Rehnsfeldt, \& Berterö, 2010).

To explain the phase of reflection within Kolb's experiential learning cycle in greater depth Rolfe's reflective framework is used.

\subsection{Rolfe's reflective practice framework}

Various models of reflective practice exist and descriptions thereof can be found in the literature. However, none can be categorised as the best; therefore each researcher has to decide which of these is most appropriate. It is necessary to understand that frameworks or models on reflection are just regarded as devices which assist the individual with reflection and cannot be used as a prescription for what to do. Therefore a framework should be viewed and used with a critical mind (Bolton, 2005; Bolton, 2008; Fowler, 2008)).

In fact experiential learning enables or allows the registered nurses to discover the possibilities or experience that may come from doing or practice. This is of extreme importance because it is believed that newly registered nurses often focus on improving technical skills rather than refining critical reasoning and communication proficiency (Thomas, Bertman and Allen (2012); Killeavy \& Moloney,(2010)).

It is further emphasised that the concept of reflective practice values the knowledge of the practitioner. As such, reflective practice models of nursing appear to value individual nursing practitioners and their contribution to nursing practice (Forneris \&PedenMcAlpine, 2006).

Rolfe's framework is centred around the questions "What?" "So what?" and "Now what?" and the relationship between these crucial questions is illustrated in Figure 5 and Table 1.

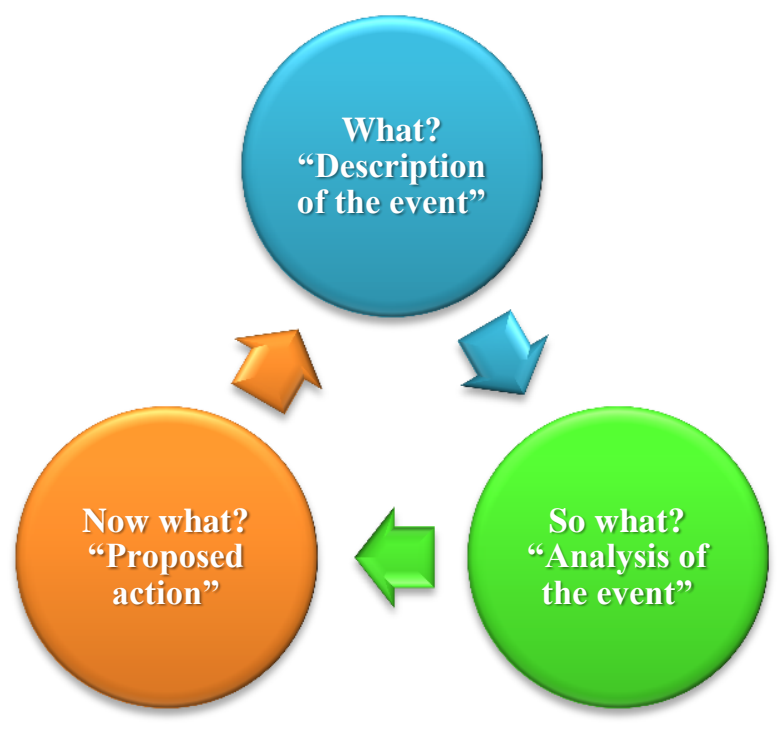

Fig. 5: Rolfe's Reflective Practice Cycle (2002)

Some ideas about reflective practice were highlighted as follows Reports from two studies of reflection in practicing nurses, were reported both of which used in-depth qualitative methods, and four nurses described reflection both as an individual activity and as mirroring, where ten members reflected together to exchange ideas and develop care. The nurses in the study further described an "anticipatory or pre-reflection occurring before an activity, as central to their practice" (Mann, Gordon and MacLeod, 2009, p.601).
Cirocco (2007, p. 406) described reflective practice as "a conscious process of thinking, analysing and learning from work situations via journal writing or regularly meeting with colleagues to examine work situations and experiences".

The development of the reflective practice programme would facilitate deep reflection among nurses by challenging and discouraging negative emotions among them which may disturb proper practices and by promoting positive emotions which motivate them to practice in an accepted and conducive approach. 
The author adopted Rolfe's framework of reflective practice as the best tool to facilitate the registered nurses' comprehension of reflective practice.

Rolfe used three simple questions to reflect a situation. He proposed a framework of reflection which consistsof three interrelated levels: "What?" "So what?" and "Now what?". Each of the levels is underscored by the leading question "What?". Rolfe's framework to enhance reflective practice is illustrated in Table1. As the table demonstrates, the three main categories of Rolfe's framework are: (1) the descriptive level of reflection (What?), (2) the theory and knowledge building level of reflection (So what?), and (3) the action-orientated level of reflection (Now what?).

In alignment with Rolfe's framework at the descriptive level the registered nurses should reflect on the nature of the problem with the aim of describing it. At this level the registered nurses should also reflect on the aspects surrounding their role in the situation and their feelings about the problem, as well as the feelings of the patients and those of their colleagues. Aspects taken into account here also involve the actions which the registered nurses have initially tried to take with regard to the particular problem. Essential to this level of reflection is also the question about the consequences for all: the patients, the registered nurses and their colleagues.

The above level leads to the second level, "theory and knowledge building", where the registered nurses reflect on the lessons they learned from the experience. At this level the registered nurses also reflect on their thoughts at the time of the experience, including the bases of their actions. They concentrate on the knowledge they could apply to the situation, whether personal, scientific or experiential knowledge. The focus is what the registered nurses could have done to improve the situation, as well as to gain new ideas about the situation.

The third level, "action-orientated" describes the actual strategising of the action plan. The nurses reflect on broader issues which need to be considered, including the consequences of their actions; they reflect on what they need to do in order to make things better. The relationship between the three crucial questions in Rolfe's framework is illustrated in Figure. 5 and table 1.

Table 1: Rolfe's Framework for Reflective Practice

\begin{tabular}{|c|c|c|}
\hline Descriptive level of reflection & Theory-and knowledge - building level of reflection & $\begin{array}{l}\text { Action-oriented (reflex- } \\
\text { ive) level of reflection }\end{array}$ \\
\hline What & So what & $\begin{array}{l}\text { Now what } \\
\text { Do I need in order to }\end{array}$ \\
\hline $\begin{array}{l}\text { Is the problem difficulty reason for being } \\
\text { stuck/reason for feeling bad/reason we don't } \\
\text { get on, etc.? }\end{array}$ & $\begin{array}{l}\text { Does this tell me/teach me/imply/mean about me/patient/others/our rela- } \\
\text { tionship/my patient's care/the model of care I am using/my attitudes/my } \\
\text { patient's attitudes, etc.? }\end{array}$ & $\begin{array}{l}\text { make things better/stop } \\
\text { being stuck/improve my } \\
\text { patient's care/resolve the } \\
\text { situation/feel better/get on } \\
\text { better, etc.? }\end{array}$ \\
\hline Was my role in the situation? & Was going through my mind as I acted? & $\begin{array}{l}\text { Broader issues need to be } \\
\text { considered if this action is } \\
\text { to be successful? }\end{array}$ \\
\hline Was I trying to achieve? & & $\begin{array}{l}\text { Might be the consequenc- } \\
\text { es of this action? }\end{array}$ \\
\hline Action did I take? & $\begin{array}{l}\text { Did I base my action on? } \\
\text { Other knowledge can I bring to the situation? }\end{array}$ & \\
\hline was the response of others & $\begin{array}{l}\text { Experiential } \\
\text { Personal } \\
\text { Scientific }\end{array}$ & \\
\hline \multicolumn{3}{|l|}{ Were the consequences... } \\
\hline $\begin{array}{l}\text { For patient? } \\
\text { For myself? } \\
\text { For others? }\end{array}$ & \multicolumn{2}{|l|}{ Could/should I have done to make it better? } \\
\hline & \multicolumn{2}{|l|}{ Is my new understanding of the situation? } \\
\hline $\begin{array}{l}\text { Feelings did it invoke... } \\
\text { In the patient? } \\
\text { In myself? } \\
\text { In others? } \\
\text { Was good/bad about the experience? }\end{array}$ & Broader issues arise from the situation? & \\
\hline
\end{tabular}

A summary of the content of the programme and how its parts relate to each other is set out in Table 2 below:

Table 2: The Relationship of the Content of the Programme: Nursing Process, Kolb's Cycle and Rolfe's Framework

\begin{tabular}{lll}
\hline nursing process & Kolb's cycle & Rolfe's framework \\
\hline $\begin{array}{l}\text { assessment of a patient: history taking, } \\
\text { physical examination }\end{array}$ & $\begin{array}{l}\text { concrete experience: focus on identification of } \\
\text { problems }\end{array}$ & What happened: what do i see? \\
nursing diagnosis & observation and reflection: consolidation & How is my relationship to the patient? How to resolve \\
& the situation? \\
planning: planning of nursing care & $\begin{array}{l}\text { care plan } \\
\text { transformation of the developed concepts, }\end{array}$ & What did i base my actions on? What other knowledge \\
implementation & $\begin{array}{l}\text { actions in new situations } \\
\text { evaluate whether the actions were successful } \\
\text { record keeping }\end{array}$ & $\begin{array}{l}\text { Possible consequences. What could i have done better? } \\
\text { record keeping }\end{array}$ \\
\hline
\end{tabular}

\section{Integration of reflective practice into nurs- ing process}

\subsection{Introduction}

The nursing process, as described previously, can be improved when integrated with Rolfe's framework of reflective practice. The researcher noticed that it is appropriate to integrate Rolfe's framework in the existing nursing process in order to enhance reflection among registered nurses. This integrated process consists of six stages which are guided by Rolfe's trigger questions of reflection: "What?", "So what?", and "Now what?" and it is displayed in figure 6 and table 3 below. 


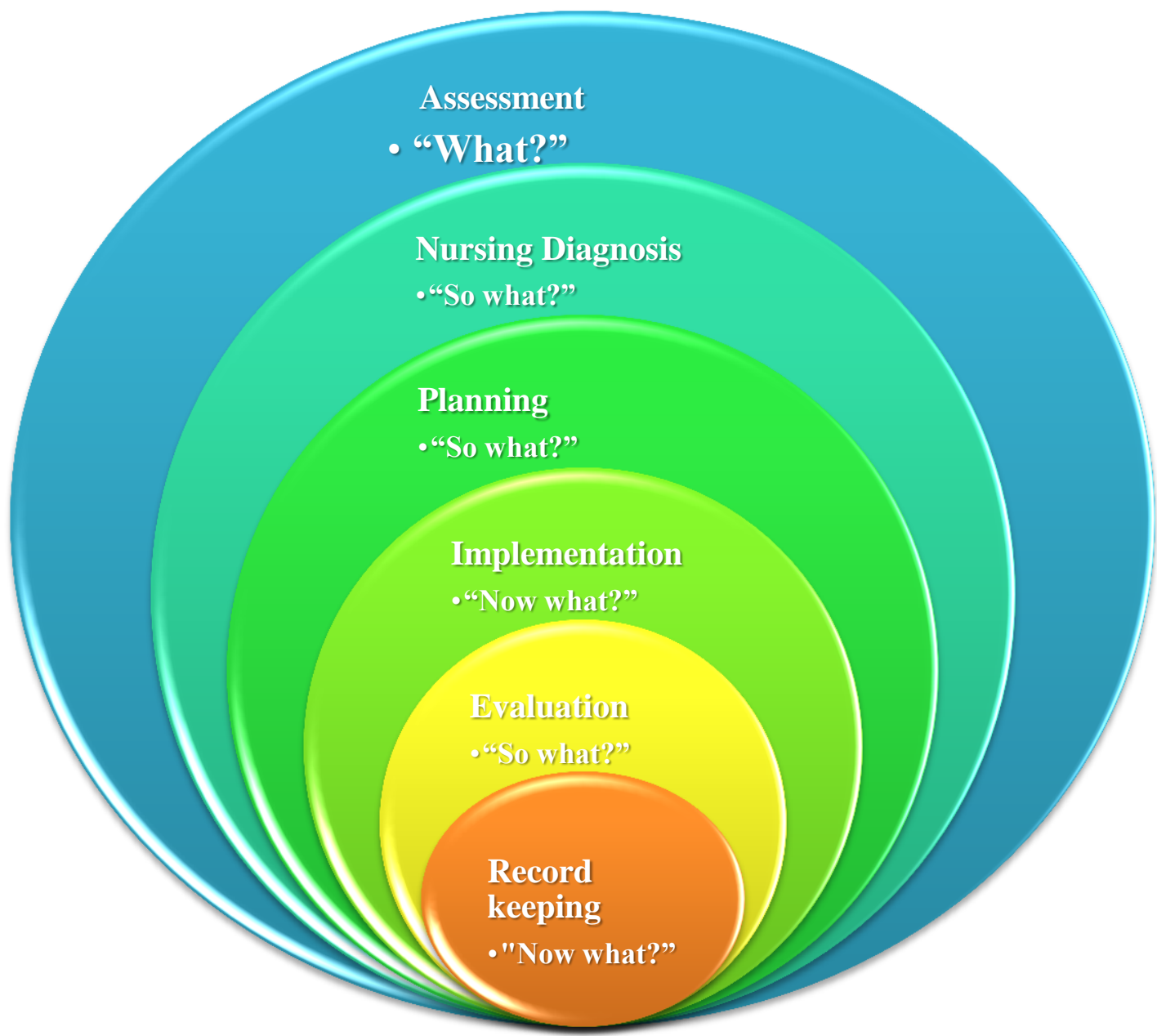

Fig. 6: Nursing Process and Rolfe's Reflective Practice Framework.

Table 3: Integration of Rolfe's Reflective Practice Framework in the Nursing Process

Nursing process:
Assessment:
An example from practice: 52 -year-old man suffering from stress. On
day two, observation shows BP of 150/120.
Nursing Diagnosis:
Stress due to psychological problems
Planning:
Explain the problem to the patient. Develop the nursing care plan.
Involve the doctor. Have the prescription in place according to the
doctor's order. Prepare the environment-for example, a quiet and re-
laxing warm room.
Implementation:
Do observation: Blood pressure should be monitored 6 hourly. Position
of the patient and position of the cuff. Accurate readings. Medication
should be given as prescribed. Proper counselling
Evaluation:
Does the treatment work or not? Is the problem addressed and im-
proved?
Record keeping:
Recording of the activities performed
Rolfe's reflective practice framework:

What?

Ask yourself about the experience. What happened? What are factors contributing to this problem (physiological and other, for example, psychological or social)?

So what?

What would be my role as a registered nurse concerning the meaning of this experience? Do I have adequate knowledge about this experience? What kind of care is my patient looking for?

So what?

Whom else do I have to involve? What have I learnt about this experience? What else I can think of as a solution to this problem? What action, based on my patient's and the family's feelings and needs? If I act in this way what would happen to my patient?

Now what?

What else could I do? What do I need to do in order to improve my patient's care? What might be the outcome of my action?

So what?

What have I learned about this experience? What knowledge and skills have I gained? What more do I need to know about this?

Now what?

What do I need to do after my actions?

What do I need to change for next time?

\section{References}

[1] Adamson, K. A. (2011). Piloting a method for comparing two experiential teaching strategies.Clinical simulations in nursing. Retrieved on 30 April, 2012 from www.elsevier.com.

[2] Asselin, M. E (2011). Reflective Narrative: A tool for learning through practice. Journal for Nurses in staff development, 27(1), 2-6. http://dx.doi.org/10.1097/NND.0b013e3181b1ba1a.

[3] Atherton, J.S. (2011) Learning and Teaching; Knowles' andragogy: an angle on adult learning (On line: UK) Retrieved on 11 August
2011

from http://www.learningandteaching.info/learning/knowlesa.htm.

[4] Ayob, A., Hussain, A., Mustafa, M.M. and Shaarani, M.F.A.S. (2011). Nurturing creativity and innovative: Thinking through experiential learning. Procedia Social and Behavioral Sciences18 (1), 247-254. http://dx.doi.org/10.1016/j.sbspro.2011.05.035.

[5] Binding, L. L., Morck, A. C. \&Moules, N. J. (2010).Learning to see the other: A vehicle of reflection.Nurse Education Today, 30(6), 591594. http://dx.doi.org/10.1016/j.nedt.2009.12.014. 
[6] Bloniasz, E. R. (2011). Caring for caretakers: A nursing process approach.Creative Nursing, 17(1), 12-15 http://dx.doi.org/10.1891/1078-4535.17.1.12.

[7] Bolton, G. (2005). Reflective Practice: Writing and professional development. London: Sage Publications.

[8] Bolton, G. (2008). Reflective practice: Writing and professional development. London: Paul Chapman.

[9] Bulson, J.A. \&Bulson, T. (2011).Nursing process and critical thinking linked to disaster preparedness, 37(5), 477-483.

[10]Caruso, S. (2010). Malcolm Knowles and the six assumptions underlying andragogy.

[11]Retrieved on 11 August 2011, from http://www.eadulteducation.org/home/adult-learning.

[12]Cirocco, M. (2007). How reflective practice improves nurses' critica thinking ability. Gastroenterology Nursing, 30(6), 405-413. http://dx.doi.org/10.1097/01.SGA.0000305221.78403.e9.

[13]Dennill, K., King, L., Swanepoel, T. (2007).Aspects of Primary Health care: Community Health care in Southern Africa. Oxford: University Press.

[14]Fidishun, D. (n.d.). Andragory and Technology: Integrating adult learning theory: As we teach with technology. Retrieved on 11 August, 2011.fromhttp://www.frank.mtsu.edu.

[15]Forneris, S. G. \&Peden-McAlpine, C. (2006). Contextual Learning: A reflective learning intervention for nursing education. International Journal of Nursing Education Scholarship, 3(1, article 17), 1-18. http://dx.doi.org/10.2202/1548-923x.1254.

[16] Fowler, J. (2008).Experiential learning and its facilitation.Nurse Education Today, 28(4), 427-433. http://dx.doi.org/10.1016/j.nedt.2007.07.007.

[17] Glassman, W. E. \&Hadad, M. (n.d.) the humanistic approach. (On line) Retrieved on 11 August, 2011.from http://www.ryerson.ca.

[18]Gustafsson, C. \&Fagerberg, I. (2004). Reflection, the way to professional development?Journal of Clinical Nursing, 13(3), 271-280. http://dx.doi.org/10.1046/j.1365-2702.2003.00880.x.

[19] Hayrinen, K. Lammintakanen, J. \&Saranto, K. (2010). Evaluation of electronic nursing documentation: Nursing process model and standardized terminologies as keys to visible and transparent nursing. International Journal of Medical Informatics, 79 (8), 554-564. http://dx.doi.org/10.1016/j.ijmedinf.2010.05.002.

[20]James, C. R. \& Clarke, B.A. (1994). Reflective practice in nursing: Issues and implications for nurse education. Nurse Education Today, 14(2), 82-90. http://dx.doi.org/10.1016/0260-6917(94)90109-0.

[21]Jarvis, P. (1992). Reflective practice and nursing.Nursing Education Today, 12(3), 31-35. http://dx.doi.org/10.1016/0260-6917(92)90059W.

[22]Jasper, M. (2003).Beginning Reflective Practice: Foundations in Nursing and Health Care. London: Nelson Thornes.

[23]Johnson, M., Sonson, R. \& Golden, T. (2010).Developing charge nurse leaders with experiential learning.Nurse Leader, 8(6), 40-46. http://dx.doi.org/10.1016/j.mnl.2010.04.003.

[24]Jones A. (2004). Teaching critical thinking and investigation of a task in introductory macroeconomics.Higher Education, Research and Development. $23 \quad$ (2) 168-181. http://dx.doi.org/10.1080/0729436042000206645.

[25] Karimi, H. (2011). Applying nursing process education in workshop framework.Procedia-Social and Behavioral Sciences, 29(2011), 561566. http://dx.doi.org/10.1016/j.sbspro.2011.11.276.

[26]Keene,P. R. (2009). Progression from low fidelity to high fidelity simulators to provide experiential learning for nursing students.Clinical Simulation in Nursing, 5(35), 143 http://dx.doi.org/10.1016/j.ecns.2009.04.047.

[27] Keese, G. (n.d.) Andragogy-Adult learning theory.Retrieved on 11 August, 2011 from http//www.teachingandlearningsources.pbworks.com.

[28]Killeavy, M., Moloney, A. (2010). Reflection in a social space: Can blogging support reflective practice for beginning teachers? Teaching and Teachers' education, 26(4), 1070-1076.

[29]Kohonen, V. (n.d).Learning to learn through reflection on experientia learning perspective.Retrieved on 09 June, 2012 from http://archive.ecml.at.

[30]Kolb, D. A. (1984).Experiential learning: Experience as the source of learning and development. New Jersey: Prentice Hall.

[31]Levett-Jones, T., Gersbach, J., Arthur, C. \& Roche J. (2011) Implementing a clinical competency assessment model that promotes critical reflection and ensures nursing graduates' readiness for professional practice. Nurse Education in Practice, 11(1), 64-69. http://dx.doi.org/10.1016/j.nepr.2010.07.004.

[32]Levett-Jones T. L. (2007) Facilitating reflective practice and selfassessment of competence through the use of narratives. Australia: Callaghan.
[33]Mann, K., Gordon, J. \& MacLeod, A. (2009). Reflection and reflective practice in health professions education: a systematic review. Advances in Health Sciences Education, 14(4), 595-621. http://dx.doi.org/10.1007/s10459-007-9090-2.

[34]Paans, W., Sermeus, W., Nieweg, R. \& Van Der Schans, C. (2010) Determinants of the accuracy of Nursing Diagnoses: Influence of ready knowledge, knowledge sources, disposition toward critical thinking and reasoning skills. Journal of Professional Nursing, 26(4), 232-241. http://dx.doi.org/10.1016/j.profnurs.2009.12.006.

[35]Quinn, F.M. \& Hughes S.J. (2007).Quinn's Principles and Practice of Nurse Education, Cheltenham: Nelson Thornes.

[36]Ranheim, A., Kärner, A., Arman, M., Rehnsfeldt, A. W. \&Berterö, C. (2010). Embodied reflection in practice-Touching the core of caring. International Journal of Nursing Practice, 16(3), 241-247. http://dx.doi.org/10.1111/j.1440-172X.2010.01836.x.

[37] Schön, D.A. (1987).Educating the Reflective Practitioner. San Francisco: Jossey-Bass.

[38] Smith, M.K. (2001). 'David A. Kolb on experiential learning', the encyclopedia of Informal Education.Retrieved on 12January 2012 from http://www.infed.org/b-explrn.htm.

[39]Smith, M.K. (2002). Malcolm Knowles, informal adult education, selfdirection and andragogy, the encyclopedia of informal education.Retrieved on 11 August 2011 from www.infed.org/thinkers/etknowl.htm

[40]Stein, D. (2000-2001). Learning- Teaching critical reflection, Exploration Hall: Articles, stories and tid bit. Retrieved on 26 September 2011 from http://www.inspiredbiz.com.

[41]Thomas, C.M., Bertram, E. \& Allen, R. (2012).Preparing for transition to professional practice: Creating a simulated blog and reflective journaling activity.Clinical Simulation in Nursing, 8(3), e87-e95. http://dx.doi.org/10.1016/j.ecns.2010.07.004.

[42] Thompson, D. N. \& Burns, H.K. (2008). Reflection: An essential element of evidence-based practice. Journal of Advanced Nursing, 34(30), 246-248. http://dx.doi.org/10.1016/j.jen.2008.02.024.

[43] Traynor, M. (2009).Humanism and its critiques in nursing research literature, Journal of Advanced Nursing, 65(7), 1560- 1567. http://dx.doi.org/10.1111/j.1365-2648.2008.04956.x.

[44]Wessels, M. (2005).Experiential Learning.Lansdowne: JutaAcademic. 